\title{
Intoxicação natural e experimental por Metternichia princeps (Solanaceae) em caprinos ${ }^{1}$
}

\author{
Juliana da Silva Prado ${ }^{2 *}$, Marilene de Farias Brito ${ }^{3}$, Saulo Andrade Caldas ${ }^{4}$, Elise Miyuki \\ Yamasaki $^{5}$, José Diomedes Barbosa ${ }^{6}$, Diogo dos Santos Maia ${ }^{7}$ e Carlos Hubinger Tokarnia ${ }^{8}$
}

\begin{abstract}
Prado J.S., Brito M.F., Caldas S.A., Yamasaki E.M., Barbosa J.D., Maia D.S. \& Tokarnia C.H. 2012. [Natural and experimental poisoning by Metternichia princeps (Solanaceae) in goats.] Intoxicação natural e experimental por Metternichia princeps (Solanaceae) em caprinos. Pesquisa Veterinária Brasileira 32(9):903-911. Projeto Sanidade Animal Embrapa/UFRRJ, Seropédica, RJ 23890-000, Brazil. E-mail: julianapradomedvet@gmail.com

From 2007 to 2009 a nephrotoxic disease of subacute course and high mortality in goats occurred on a farm in the county of Itaguaí, Rio de Janeiro. Metternichia princeps, a plant of the Solanaceae family, was suspected to be the cause. Through experiments in goats the clinical-pathological picture of poisoning by the plant and the lethal dose were established. For the experiments 12 young and adult goats of different races, both sexes and with weights above $15 \mathrm{~kg}$ were used. The goats that received $30 \mathrm{~g} / \mathrm{kg}$ in 5 days, $15 \mathrm{~g} / \mathrm{kg}$ in 3 days, single doses of $10 \mathrm{~g} / \mathrm{kg}$ and $5 \mathrm{~g} / \mathrm{kg}$, all died. Of two goats that received single doses of $2.5 \mathrm{~g} / \mathrm{kg}$, one died but the other did not show any clinical sign; a goat that received the single dose of $1.25 \mathrm{~g} / \mathrm{kg}$ also did not show any symptom of poisoning. First clinical signs were observed from 7 hours to $46 \mathrm{~h} 45 \mathrm{~min}$ after the plant intake. The clinical course varied from $3 \mathrm{~h} 6 \mathrm{~min}$ to $126 \mathrm{~h} 40 \mathrm{~min}$. First clinical signs were loss of appetite, adipsia, apathy and reluctance to move. After the animals entered in sternal decubitus and when they were placed in standing position, they kept their front limbs flexed, supported only by the posterior limbs on the floor until evolving into flexion of all four limbs followed by lateral decubitus. Postmortem examination revealed edema of the perirenal adipose tissue, pale kidneys which on the cut-surface showed whitish stripes from the cortex to the medullar area. At histopathology, severe coagulative necrosis of epithelial cells of the kidney tubules was seen. Compared with the natural cases, the goats experimentally poisoned by $M$. princeps, presented a similar clinic-pathological picture. By these experiments it could be proved that Metternichia princeps is the toxic plant that causes a nephrotoxic disease in goats in the Rio de Janeiro area; the minor lethal dose was $2,5 \mathrm{~g} / \mathrm{kg}$ in the experiments.
\end{abstract}

INDEX TERMS: Poisonous plants, Metternichia princeps, Solanaceae, pathology, ruminants.

\footnotetext{
${ }^{1}$ Recebido em 2 de abril de 2012.

Aceito para publicação em 1 de junho de 2012.

Parte da Dissertação de Mestrado do primeiro autor

${ }^{2}$ Mestranda do Curso de Pós-Graduação em Ciências Veterinárias, área de concentração em Sanidade Animal, Universidade Federal Rural do Rio de Janeiro (UFRRJ), Seropédica, RJ 23890-000, Brasil. *Autor para correspondência: julianapradomedvet@gmail.com

${ }^{3}$ Departamento de Epidemiologia e Saúde Pública, Instituto de Veterinária, UFRRJ, BR $465 \mathrm{Km} \mathrm{7,} \mathrm{Seropédica,} \mathrm{RJ.} \mathrm{E-mail:} \mathrm{marilene@ufrrj.br}$

${ }^{4}$ Departamento de Medicina e Cirurgia Veterinária, Instituto de Veterinária, UFRRJ, Seropédica, RJ.

${ }^{5}$ Doutoranda do Curso de Pós-Graduação em Ciências Veterinárias, área de concentração em Sanidade Animal.

${ }^{6}$ Central de Diagnóstico Veterinário (Cedivet), Faculdade de Medicina Veterinária, Universidade Federal do Pará (UFPA), Rua Maximino Porpino da Silva 1000, Pirapora, Castanhal, PA 68740-080, Brasil.

${ }^{7}$ Médico Veterinário, autônomo, Rio de Janeiro.

${ }^{8}$ Departamento de Nutrição Animal e Pastagem, Instituto de Zootecnia, UFRRJ, Seropédica, RJ.
}

RESUMO.- Entre os anos de 2007 e 2009 ocorreu uma doença nefrotóxica de evolução subaguda com alta mortandade em caprinos em uma propriedade no município de Itaguaí, estado do Rio de Janeiro. Levantou-se a suspeita de que Metternichia princeps, planta pertencente à família Solanaceae, seria a causa. Através de experimentação em caprinos o quadro clínico-patológico de intoxicação por esta planta e a dose letal foram estabelecidos. Na experimentação foram utilizados 12 caprinos de diferentes raças, de ambos os sexos, jovens a adultos, com pesos acima de $15 \mathrm{~kg}$. Os animais que receberam as doses de $30 \mathrm{~g} / \mathrm{kg}$ em 5 dias, $15 \mathrm{~g} / \mathrm{kg}$ em 3 dias, doses únicas de $10 \mathrm{~g} / \mathrm{kg}$ e de $5 \mathrm{~g} / \mathrm{kg}$, morreram. Dos três animais que receberam as doses únicas de $2,5 \mathrm{~g} / \mathrm{kg}$, dois morreram e um não apresentou sinais clínicos e o animal que recebeu a dose única de $1,25 \mathrm{~g} / \mathrm{kg}$, também não apresentou sinais clínicos. 0 início dos sinais 
clínicos após a administração da planta variou entre $7 \mathrm{~h}$ e 46h45min. A evolução variou entre 3h6min e 126h40min. Os primeiros sinais clínicos apresentados foram inapetência, adipsia, apatia e relutância ao movimento. Em seguida os animais entravam em decúbito esternal e ao serem colocados em estação, mantinham os membros anteriores flexionados, apoiavam apenas os posteriores no chão até evoluírem para flexão dos quatro membros e seguia-se o decúbito lateral. À necropsia destacaram-se o edema de tecido adiposo perirrenal, rins pálidos e, ao corte, com estriação esbranquiçada desde o córtex até a região medular. À histopatologia foi verificada acentuada necrose coagulativa das células epiteliais dos túbulos uriníferos. Comparativamente aos casos naturais, os caprinos intoxicados experimentalmente por M. princeps apresentaram quadro clínico-patológico semelhante. Desta maneira foi comprovado que Metternichia princeps é responsável pela doença nefrotóxica em caprinos no Rio de Janeiro; a menor dose que causou a morte dos caprinos nos experimentos foi $2,5 \mathrm{~g} / \mathrm{kg}$.

TERMOS DE INDEXAÇ̃̃O: Plantas tóxicas, Metternichia princeps, Solanaceae, ruminante, patologia.

\section{INTRODUÇÃO}

No Brasil, as mais importantes plantas nefrotóxicas de interesse pecuário são Thiloa glaucocarpa, da família Combretaceae, e diversas espécies do gênero Amaranthus, da família Amaranthaceae. Adicionalmente há suspeitas de que Dimorphandra mollis, da família Leguminosae Caesalpinoideae, árvore do cerrado brasileiro, cujas favas têm sido demonstradas através da experimentação serem tóxicas para bovinos, possa ser a causa de mortandades (Tokarnia et al. 2012).

Metternichia princeps é uma árvore da família Solanaceae, conhecida como "jasmim-do-morro" (Schwirkowski 2009), "café-do-mato" (Lopes et al. 2004) e "trombeteira" (Lorenzi 2009). Sua distribuição se estende desde a Bahia até o Rio de Janeiro, em áreas predominantemente de Mata Atlântica (Lorenzi 2009), Caatinga (Stehmann et al. 2010) e Restinga (Barbará \& Carvalho 1996).

Entre os anos de 2007 e 2009 ocorreu doença nefrotóxica letal, de evolução subaguda em caprinos, em uma propriedade no município de Itaguaí, estado do Rio de Janeiro. Levantou-se a suspeita de que $M$. princeps seria a causa (Caldas et al. 2011). Para comprovação desta suspeita, estabeleceu-se, através de experimentação em caprinos, o quadro clínico-patológico de intoxicação por M. princeps e se comparou os quadros naturais e experimentais. Também foi estabelecida a dose letal da planta para caprinos.

\section{MATERIAL E MÉTODOS}

Material botânico (galhos com folhas, flores e frutos) da planta suspeita foi coletado em 1 de dezembro de 2009, para identificação no Departamento de Botânica do Instituto de Biologia da Universidade Federal Rural do Rio de Janeiro.

\section{Intoxicação natural}

Os caprinos afetados pela doença na propriedade em Itaguaí, RJ, à medida que apresentavam sinais clínicos, foram encaminhados ao Setor de Anatomia Patológica, Projeto Sanidade Animal, Embrapa/Universidade Federal Rural do Rio de Janeiro (SAP/
PSA/UFRRJ). Para observação os animais foram mantidos em baias individuais de alvenaria, medindo $3 \times 4 \mathrm{~m}$, com cocho e bebedouro. Foram acompanhados 10 animais doentes. Destes, 4 caprinos eram da raça Saanen, fêmeas, jovens a adultos; 5 eram Anglo Nubianas, fêmeas, adultas e um animal era mestiço de Anglo Nubiana, fêmea, adulta. Adicionalmente um animal foi eutanasiado e necropsiado na propriedade.

Foram realizadas visitas à propriedade no município de Itaguaí, RJ, para observação do local onde se encontravam os animais, do tipo de manejo, da vegetação existente no pasto e para a verificação das manifestações clínico-patológicas nestes animais.

Os animais doentes que foram levados ao SAP/PSA/UFRRJ, eram alimentados com capim elefante (Pennisetum purpureum), feno e capim angola (Brachiaria mutica); a água ficava à disposição.

Foram realizados exames clínicos, e aferidos temperatura retal, frequências cardíaca e respiratória e movimentos ruminais. Avaliou-se ainda a postura, atitude, apetite, sede, e aspectos das fezes e da urina. Sangue foi coletado da veia jugular para realização de provas de função hepática, renal e dosagens de cálcio, sódio e potássio sérico.

Os exames físico-químicos da urina foram realizados com tiras reagentes (Biocolor-Bioeasy).

\section{Intoxicação experimental}

Foram usados 12 caprinos das raças Saanen, Boer, Parda alpina e Toggenburg, de ambos os sexos, jovens a adultos, com pesos acima de $15 \mathrm{~kg}$. Dentre esses, um animal serviu como controle.

0 estudo experimental foi realizado em dois locais: a primeira parte na propriedade em Itaguaí, RJ, para se fazer observações sobre a ingestão espontânea da planta e a segunda parte com administrações controladas nas instalações do SAP/PSA/UFRRJ.

Os três animais levados para observação no sítio foram mantidos em baias individuais de madeira e piso em alvenaria forrado com maravalha, medindo $3 \times 1,5 \mathrm{~m}$, com cocho e bebedouro. 0 s outros nove animais dos experimentos foram mantidos no SAP/ PSA/UFRRJ.

\section{Experimentos realizados na propriedade}

Antes de serem introduzidos no pasto com M. princeps, os animais foram tratados contra endoparasitos e ectoparasitos, pesados e levados à propriedade para prévia adaptação.

Os exames clínicos foram realizados antes e depois de os animais voltarem do pastejo, verificando-se parâmetros como temperatura retal, frequências cardíaca e respiratória e movimentos ruminais.

Os caprinos eram mantidos em jejum pela manhã e soltos no pasto das 13 às 17 horas. Ao retornarem recebiam no cocho capim elefante (Pennisetum purpureum) picado e fubá de milho. Por volta das 21 horas, era oferecida ração (SOMA® Cabra manutenção) no cocho. 0 período de observação dos animais na propriedade foi de 11 dias.

\section{Experimentos realizados no SAP/PSA/UFRRJ}

Os animais passaram por período de adaptação, alimentados com capim elefante (Pennisetum purpureum) e bebiam água à vontade.

A planta utilizada antes de cada experimento foi coletada na data da administração, pela manhã. Antes de cada experimento, os animais foram vermifugados, pesados e mantidos em jejum por 24 horas. Foram submetidos a exames clínicos antes e durante os experimentos. Sangue e urina foram coletados da veia jugular antes e durante os experimentos para realização de exames de função hepática e renal, e dosagens de cálcio, sódio e potássio sérico. 
As doses administradas foram $30 \mathrm{~g} / \mathrm{kg}$ em 5 dias, $15 \mathrm{~g} / \mathrm{kg} \mathrm{em} 3$ dias, doses únicas de $10 \mathrm{~g} / \mathrm{kg}, 5 \mathrm{~g} / \mathrm{kg}, 2,5 \mathrm{~g} / \mathrm{kg}$ e $1,25 \mathrm{~g} / \mathrm{kg}$.

\section{Necropsias e histopatologia}

Todas as necropsias, com exceção de um caso natural de intoxicação e de dois caprinos que morreram nos experimentos realizados na propriedade em Itaguaí, foram realizadas no SAP/ PSA/UFRRJ. Os tecidos coletados foram fixados em formol a $10 \%$ tamponado, processados pelos métodos rotineiros, cortados a $5 \mu$, corados pela HE e pelo método Tricrômico de Masson.

\section{RESULTADOS}

O material botânico foi depositado no Herbário RBR, e recebeu o número de registro (exsicata) RBR 35108. Foi identificado como Metternichia princeps da família Solanaceae. (Fig.1-4)

\section{Intoxicação natural}

A propriedade com o problema situa-se no município de Itaguaí, RJ, em área de proteção ambiental, por estar inserida em área de Mata Atlântica.

0 histórico da ocorrência das intoxicações foi obtido durante as visitas à propriedade e durante o período passado na mesma, para observação da ingestão espontânea da planta.

0 proprietário relatou que os animais sempre foram criados em regime de confinamento e que começaram a adoecer quando houve a mudança para o sistema de semi-confinamento. Decidiu-se soltar os animas num determinado pasto da propriedade. Os animais eram criados em baias individuais ou em grupos, separados por sexo e por fase de desenvolvimento. Os caprinos recebiam ração SOMA® (Cabra manutenção) pela manhã. No início da tarde eram levados ao pasto, e retornavam às baias no final do dia. À noite, por volta das 21 horas eram alimentados com capim elefante (Pennisetum purpureum) picado e concentrado.

Do sétimo ao décimo dia após a introdução no pasto, morreram 11 de um total de 70 caprinos. Um médico veterinário realizou a necropsia de um dos animais e encontrou lesões renais. Concluiu que se tratava de falta de adaptação dos animais ao novo regime. Decidiu-se manter os animais soltos no pasto em dias alternados até a completa adaptação. A orientação foi seguida, porém as mortes continuaram (morreram mais quatro caprinos). Foi então estabelecido contato com a equipe do SAP/PSA/UFRRJ. Nesta ocasião o proprietário adquiriu outras 14 cabras Anglo $\mathrm{Nu}$ bianas, que também foram criadas no mesmo sistema de semi-confinamento e várias também morreram.

A evolução e o quadro clínico-patológico da doença foram então acompanhados pelos veterinários do SAP/PSA/ UFRRJ. Dois a três dias após levados ao pasto, os caprinos apresentavam como principais sinais clínicos apatia, ema-
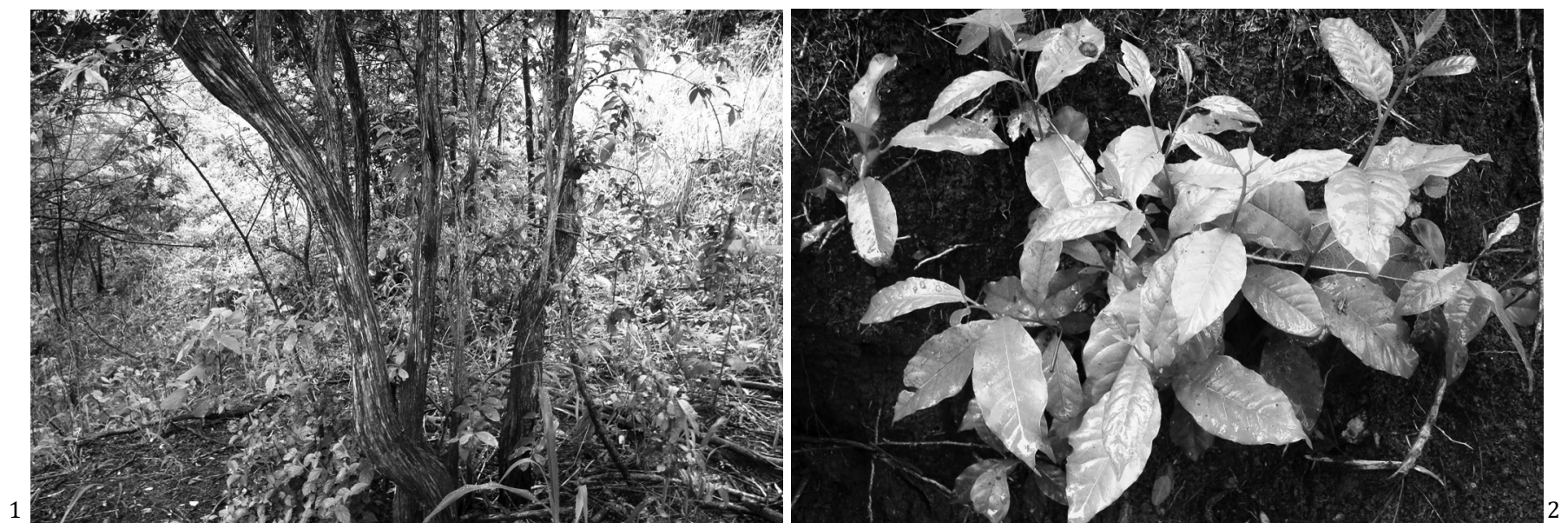

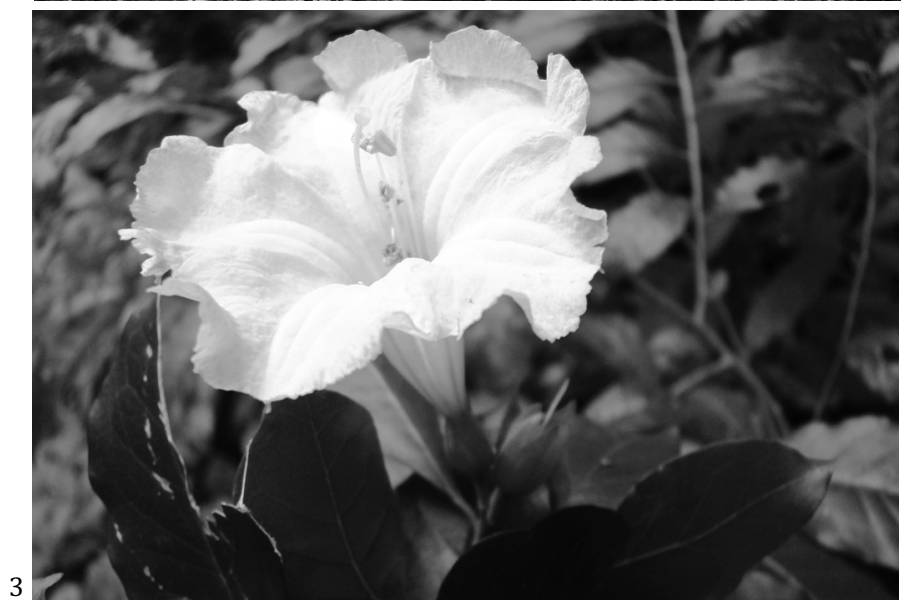

Fig.1. Detalhes do tronco de Metternichia princeps.

Fig.3. Inflorescência de Metternichia princeps.

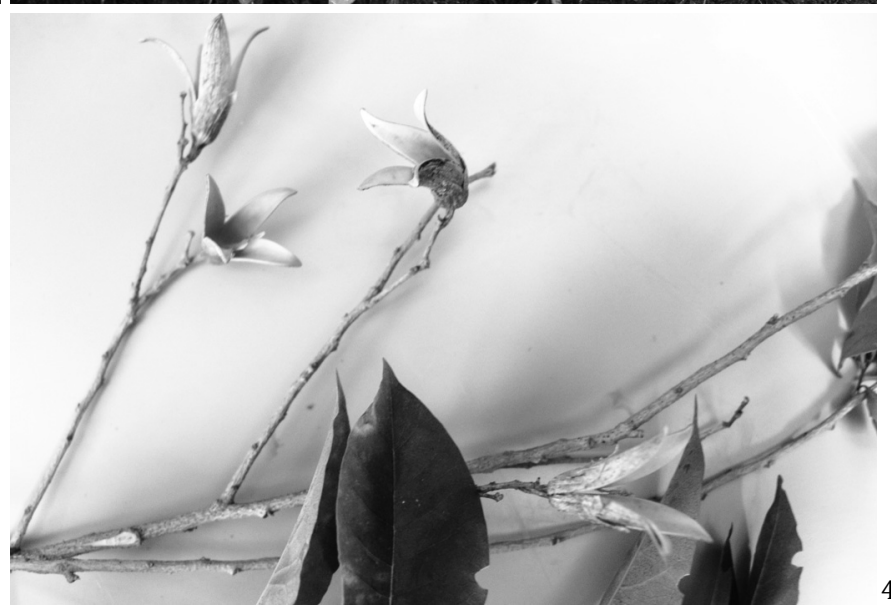

Fig.2. Brotação de Metternichia princeps.

Fig.4. Metternichia princeps, galho com frutos. 
grecimento progressivo, fraqueza muscular até acentuada atrofia, relutância ao movimento, decúbito esternal e posteriormente decúbito lateral. Ao serem colocados em estação mantinham os membros anteriores flexionados e apoiavam apenas os posteriores no chão, até evoluírem para flexão dos quatro membros. (Fig.6)

$\mathrm{O}$ apetite, em geral, era mantido e a temperatura, frequências cardíaca e respiratória e movimentos ruminais per-

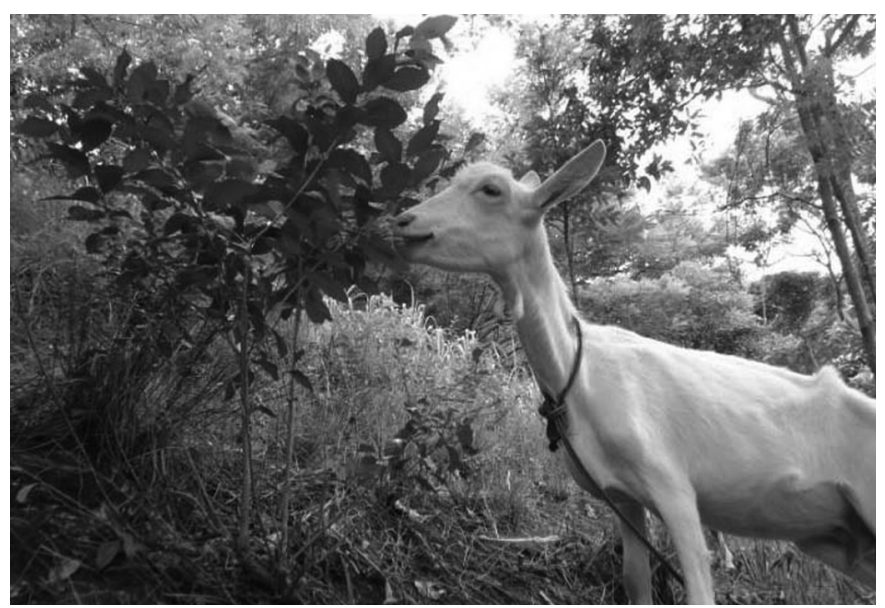

Fig.5. Intoxicação experimental (ingestão espontânea da planta no pasto) por Metternichia princeps (Caprino 5803, SAP 31954).

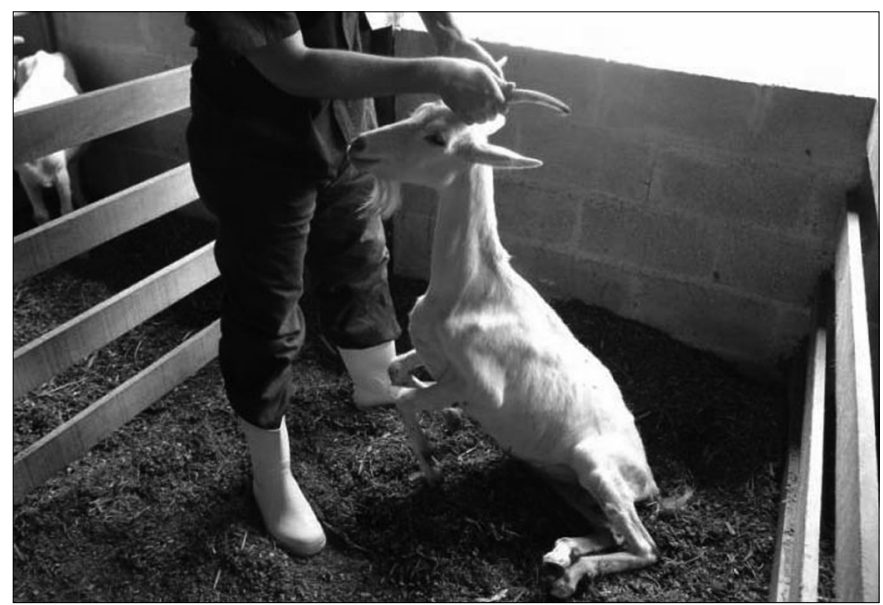

Fig.6. Animal magro e incapaz de se manter em estação. Intoxicação natural por Metternichia princeps (Caprino 5794, SAP 31761).

Quadro 1. Bioquímica sanguínea na intoxicação natural por Metternichia princeps em caprinos

\begin{tabular}{lcccccc}
\hline \multirow{2}{*}{ Parâmetros clínicos } & \multicolumn{2}{c}{$\begin{array}{c}\text { Caprino 5799 } \\
\text { (SAP 31835) }\end{array}$} & & \multicolumn{3}{c}{$\begin{array}{c}\text { Caprino 5800 } \\
\text { (SAP 31836) }\end{array}$} \\
\cline { 2 - 3 } \cline { 6 - 7 } & T1 & T2 & & T1 & T2 & T3 \\
\hline \multirow{2}{*}{ ALT } & 15 & 157 & & 15 & 94 & 83 \\
AST & 377 & 319 & & 78 & 172 & 146 \\
UREIA & 75 & 71 & & 464 & 78 & 68 \\
CREATININA & 1,8 & 1,7 & & 6,0 & 1,4 & 1,4 \\
CK & - & - & & - & - & - \\
DHL & - & - & & - & - & - \\
Ca & 8,2 & 7,34 & & - & 8,03 & 6,65 \\
P & 0,00 & 0,00 & & - & 0,00 & 9,2 \\
Na & 149 & 146 & & - & 145 & 149 \\
K & 4,4 & 3,9 & & - & 5,0 & 4,7
\end{tabular}

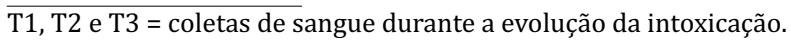

maneciam normais até próximo à morte. A evolução variou de alguns dias até, às vezes, algumas semanas. Quanto aos exames laboratoriais dos animais intoxicados naturalmente, nos dois caprinos que tiveram exames bioquímicos do soro sanguíneo realizado, as análises demonstraram que a ALT apresentou aumento na atividade enquanto a atividade da AST se manteve dentro da normalidade. Foi observado, ainda, aumento na concentração de ureia nos dois animais, enquanto que a concentração de creatinina aumentou somente na primeira coleta de um dos dois animais, retornando à normalidade nas coletas seguintes. (Quadro 1)

À necropsia se destacavam, em todos os animais afetados pela doença, caquexia, edema de tecido adiposo perirrenal, rins pálidos com estriações esbranquiçadas do córtex até a região medular, evidenciação do padrão lobular do fígado e ocasionalmente ulceração na língua, faringe e no esôfago. (Fig.7-9)

Ao exame histopatológico, foi verificada nos rins em 4 dos 10 caprinos que morreram naturalmente, necrose tubular tóxica, caracterizada por necrose coagulativa de grupos de túbulos uriníferos no córtex renal. As células epiteliais estavam transformadas em massas eosinófilas amorfas, que preenchiam a luz dos túbulos, externamen-

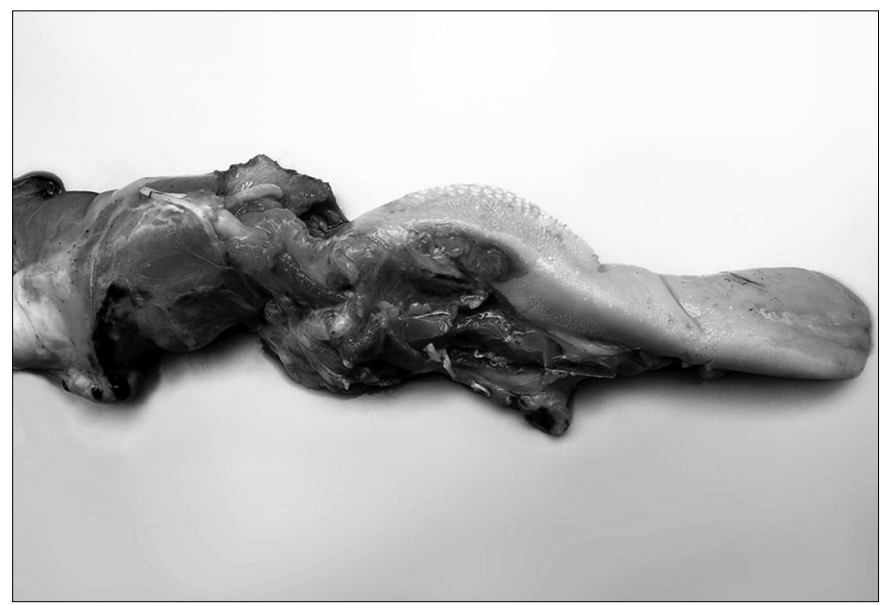

Fig.7. Língua com úlcera na intoxicação natural por Metternichia princeps (Caprino 5798, SAP 31796).

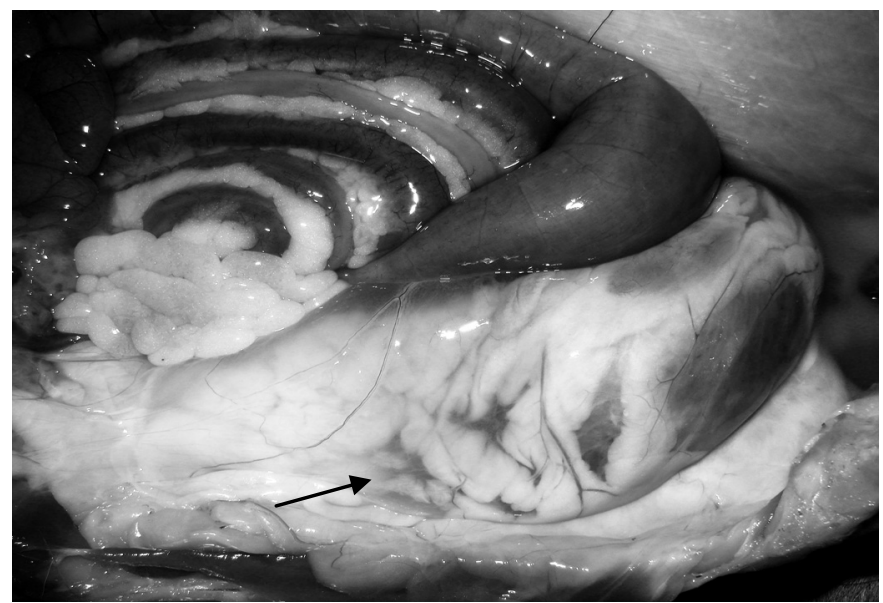

Fig.8. Edema da gordura perirrenal (seta) na intoxicação natural por Metternichia princps (Caprino 5795, SAP 31793). 
Quadro 2. Lesões microscópicas da intoxicação natural por Metternichia princeps em caprinos

\begin{tabular}{|c|c|c|c|c|c|c|c|c|c|}
\hline \multirow[t]{3}{*}{ Animal (SAP) } & \multicolumn{4}{|c|}{ Fígado } & \multicolumn{4}{|c|}{ Rim } & \multirow{3}{*}{$\begin{array}{c}\text { Detritos celula } \\
\text { res na luz dos } \\
\text { túbulos }\end{array}$} \\
\hline & \multirow[t]{2}{*}{$\begin{array}{l}\text { Necrose incipiente } \\
\text { de hepatócitos }\end{array}$} & \multirow[t]{2}{*}{$\begin{array}{l}\text { Vacuolização em } \\
\text { vacúolos grandes }\end{array}$} & \multirow{2}{*}{$\begin{array}{c}\text { Hepatócitos com } \\
\text { aspecto de células } \\
\text { vegetais }\end{array}$} & \multirow[t]{2}{*}{$\begin{array}{c}\text { Necrose } \\
\text { coagulativa }\end{array}$} & \multicolumn{2}{|c|}{$\begin{array}{l}\text { Cilindros hialinos e pre } \\
\text { cipitados de albumina }\end{array}$} & \multicolumn{2}{|c|}{$\begin{array}{l}\text { Dilatação de túbu } \\
\text { los uriníferos }\end{array}$} & \\
\hline & & & & & Córtex & Medula & Córtex & $\overline{\text { Medula }}$ & \\
\hline $\begin{array}{l}\text { Caprino5791 } \\
\text { (SAP 31129) }\end{array}$ & - & - & - & +++ & +++ & +++ & +++ & - & + \\
\hline $\begin{array}{l}\text { Caprino } 5792 \\
\text { (SAP 31130) }\end{array}$ & + Centrolobular & - & - & ++ & ++ & ++ & +++ & - & ++ \\
\hline $\begin{array}{l}\text { Caprino } 5793 \\
\text { (SAP 31131) }\end{array}$ & - & - & - & - & ++ & ++ & +++ & + & - \\
\hline $\begin{array}{l}\text { Caprino } 5794 \\
\text { (SAP 31761) }\end{array}$ & - & - & ++ & - & + & + & ++ & + & + \\
\hline $\begin{array}{l}\text { Caprino } 5795 \\
\text { (SAP } 31793 \text { ) }\end{array}$ & $+(+)$ Centrolobular & + Centrolobular & - & +++ & + & - & + & - & + \\
\hline $\begin{array}{l}\text { Caprino } 5796 \\
\text { (SAP 31794) }\end{array}$ & $+(+)$ & $\begin{array}{l}\text { (+) Centrolobular } \\
\text { e Z. intermediária }\end{array}$ & + & - & ++ & + & ++ & - & - \\
\hline $\begin{array}{l}\text { Caprino } 5797 \\
\text { (SAP 31795) }\end{array}$ & - & - & - & ++ & +++ & +++ & +++ & - & + \\
\hline $\begin{array}{l}\text { Caprino } 5798 \\
\text { (SAP 31796) }\end{array}$ & + Centrolobular & - & ++ & - & + & $(+)$ & +++ & - & $(+)$ \\
\hline $\begin{array}{l}\text { Caprino } 5799 \\
\text { (SAP 31835) }\end{array}$ & - & + Centrolobular & +++ & - & $(+)$ & - & + & - & - \\
\hline $\begin{array}{l}\text { Caprino } 5800 \\
\text { (SAP 31836) }\end{array}$ & - & - & +++ & - & $(+)$ & - & - & - & - \\
\hline
\end{tabular}

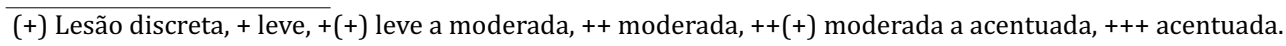

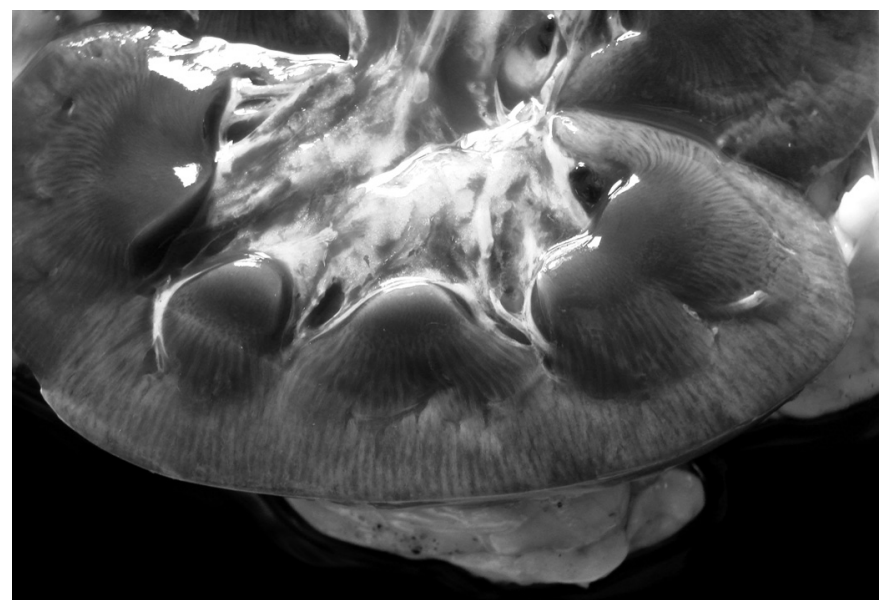

Fig.9. Superfície de corte do rim com estriações pálidas. Intoxicação natural por Metternichia princeps (Caprino 5795, SAP 31793).

te delimitadas apenas pela membrana basal. Na luz de túbulos uriníferos, tanto no córtex quanto na medula, havia cilindros hialinos e precipitados de albumina, e menos frequentemente neutrófilos e detritos celulares. Em quase todos os casos havia dilatação dos túbulos uriníferos, principalmente no córtex; as células epiteliais desses túbulos encontravam-se achatadas. (Fig.10 e 12)

No fígado foi constatada vacuolização em vacúolos grandes, em graus discreto a leve. Em alguns casos os hepatócitos assumiram aspecto de células vegetais devido à tumefação. Havia necrose incipiente (núcleo com cromatina condensada e citoplasma avermelhado) dos hepatócitos, de distribuição aleatória. Os demais órgãos não apresentaram alterações significativas. A coloração pelo Tricrômico de Masson resultou negativa em todos os rins. Detalhes das alterações histológicas constam no Quadro 2.

\section{Experimentos realizados na propriedade e no SAP/ PSA/UFRRJ}

O delineamento e desfecho da intoxicação experimental por Metternichia princeps constam no Quadro 3.

Dos três animais levados à propriedade para observação da ingestão espontânea de M. princeps, apenas dois ingeriram a planta e morreram. (Fig.5)

Nos experimentos realizados no SAP/PSA/UFRRJ, os animais que receberam as doses de $30 \mathrm{~g} / \mathrm{kg}$ em 5 dias, $15 \mathrm{~g} / \mathrm{kg}$ em 3 dias, doses únicas de $10 \mathrm{~g} / \mathrm{kg}, 5 \mathrm{~g} / \mathrm{kg}$ morreram. Dos três animais que receberam as doses únicas de $2,5 \mathrm{~g} / \mathrm{kg}$, dois morreram e um não apresentou sinais clínicos; o animal que recebeu a dose única de $1,25 \mathrm{~g} / \mathrm{kg}$ também não apresentou sinais clínicos.

Todos os parâmetros clínicos (temperatura, frequências cardíaca e respiratória, movimentos ruminais, cor de

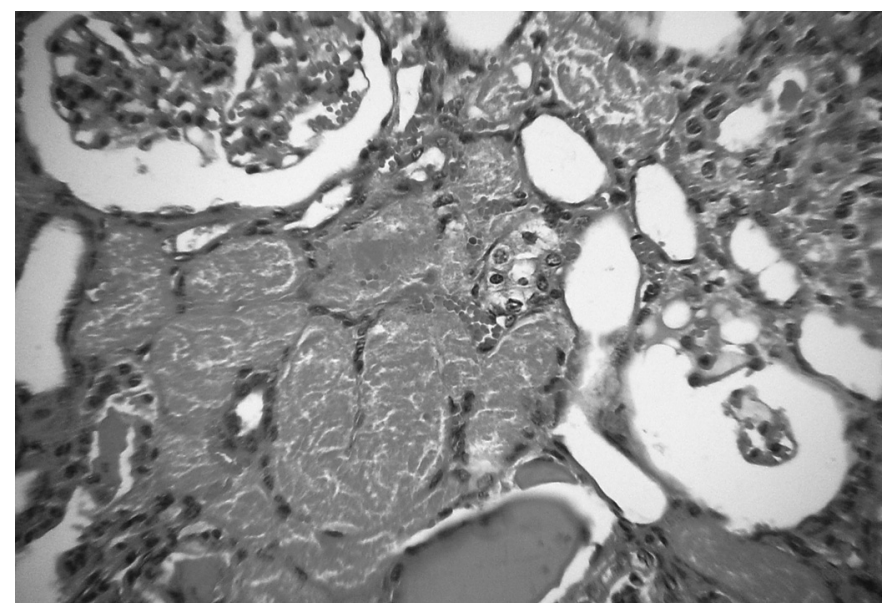

Fig.10. Necrose de coagulação e dilatação de túbulos uruníferos, na intoxicação natural por Metternichia princeps (Caprino 5791, SAP 31129). HE, obj.25x. 


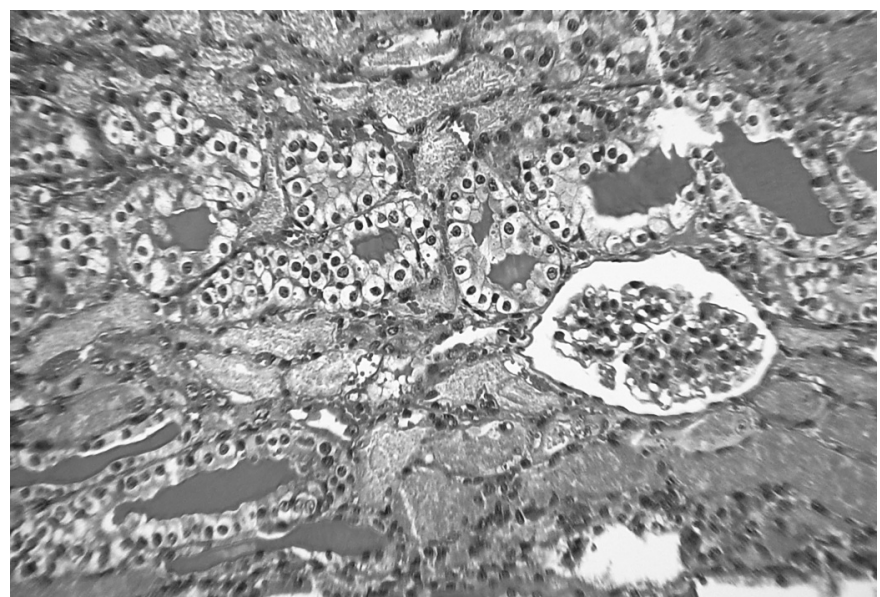

Fig.11. Vacuolização e picnose de células epiteliais de túbulos uriníferos; nota-se ainda a presença de cilindros hialinos na luz de túbulos, na intoxicação experimental por Metternichia princeps (Caprino 5802, SAP 31800). HE, obj.16x.

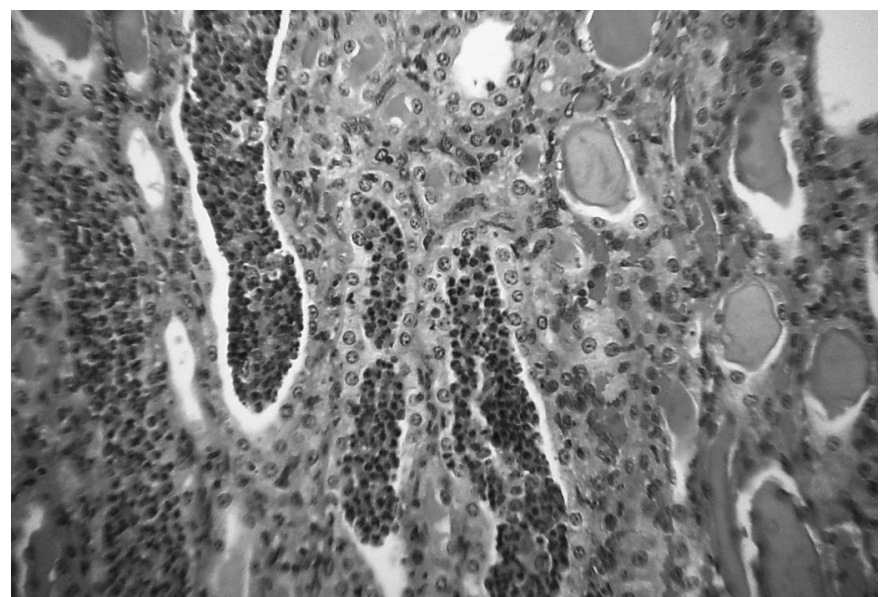

Fig.12. Túbulos uriníferos preenchidos por detritos celulares; nota-se ainda a presença de cilindros hialinos na luz de túbulos, na intoxicação natural por Metternichia princeps. (Caprino 5792, SAP 31130). HE, obj.16x.

Quadro 3. Delineamento experimental e desfecho da intoxicação por Metternichia princeps em caprinos

\begin{tabular}{|c|c|c|c|c|c|c|c|c|}
\hline $\begin{array}{l}\text { Animal } \\
\text { (SAP) }\end{array}$ & Raça & $\begin{array}{l}\text { Peso } \\
(\mathrm{kg})\end{array}$ & Idade & Sexo & Dose & Início dos sintomas & Evolução & Desfecho \\
\hline $\begin{array}{r}\text { Caprino } 5801 \\
\text { (SAP 31799) }\end{array}$ & Parda Alpina & 13 & Jovem & $\mathrm{F}$ & $15 \mathrm{~g} / \mathrm{kg}$ em 3 dias & 24 horas & 24 horas & Morreu \\
\hline $\begin{array}{l}\text { Caprino } 5802 \\
\text { SAP }(31800)\end{array}$ & Saanen & 33 & Adulto & $\mathrm{F}$ & $30 \mathrm{~g} / \mathrm{kg}$ em 5 dias & $29 \mathrm{~h}: 30 \mathrm{~min}$ & 72 horas & Morreu \\
\hline $\begin{array}{l}\text { Caprino 5803 } \\
\text { (SAP 31954) }\end{array}$ & Saanen & 18 & Jovem & $\mathrm{F}$ & Ingestão espontânea & $\begin{array}{l}\text { Não foram observa } \\
\text { dos sinais clínicos }\end{array}$ & $\begin{array}{l}\text { Não foram observados } \\
\text { sinais clínicos }\end{array}$ & $\begin{array}{l}\text { Encontrado morto } \\
\text { no } 3^{0} \text { dia após ser } \\
\text { solto no pasto }\end{array}$ \\
\hline $\begin{array}{l}\text { Caprino 5804 } \\
\text { (SAP 31955) }\end{array}$ & Toggenburg & 37 & Adulto & $\mathrm{F}$ & Ingestão espontânea & 42 horas & 96 horas & Morreu \\
\hline $\begin{array}{l}\text { Caprino 5805 } \\
\text { (SAP 31956) }\end{array}$ & Saanen & 35 & Adulto & $\mathrm{F}$ & $10 \mathrm{~g} / \mathrm{kg}$ & 7 horas & 25 horas & Morreu \\
\hline $\begin{array}{l}\text { Caprino 5806 } \\
\text { (SAP 32234) }\end{array}$ & Boer & 48 & Adulto & M & $10 \mathrm{~g} / \mathrm{kg}$ & $13 \mathrm{~h}: 25 \mathrm{~min}$ & $3 \mathrm{~h}: 6 \mathrm{~min}$ & Morreu \\
\hline $\begin{array}{l}\text { Caprino } 5807 \\
\text { (SAP 32235) }\end{array}$ & Boer & 49 & Adulto & M & $5 \mathrm{~g} / \mathrm{kg}$ & $29 \mathrm{~h}: 10 \mathrm{~min}$ & $35 \mathrm{~h}: 30 \mathrm{~min}$ & Morreu \\
\hline $\begin{array}{l}\text { Caprino } 5808 \\
\text { (SAP 32238) }\end{array}$ & Boer & 49,5 & Adulto & $\mathrm{F}$ & $2,5 \mathrm{~g} / \mathrm{kg}$ & $42 \mathrm{~h}: 35 \mathrm{~min}$ & $\begin{array}{l}\text { 126h:40min } \\
\text { (aprox. } 4 \text { dias) }\end{array}$ & Morreu \\
\hline Caprino 5809 & Toggenburg & 22 & Jovem & $\mathrm{M}$ & $1,25 \mathrm{~g} / \mathrm{kg}$ & Sem sinais clínicos & Sem sinais clínicos & Sem sinais clínicos \\
\hline $\begin{array}{l}\text { Caprino } 5810 \\
\text { (SAP 32245) }\end{array}$ & Saanen & 27,8 & Jovem & $\mathrm{F}$ & $2,5 \mathrm{~g} / \mathrm{kg}$ & Sem sinais clínicos & $\begin{array}{c}\text { 123h:46min } \\
\text { (aprox. } 4 \text { dias) }\end{array}$ & Morreu \\
\hline Caprino 5811 & Saanen & 22,1 & Jovem & $\mathrm{F}$ & $2,5 \mathrm{~g} / \mathrm{kg}$ & Sem sinais clínicos & Sem sinais clínicos & Sem sinais clínicos \\
\hline Caprino 5812 & Boer & 62 & Adulto & $\mathrm{M}$ & - & Sem sinais clínicos & Sem sinais clínicos & Sem sinais clínicos \\
\hline
\end{tabular}

mucosas) avaliados antes e durante os experimentos foram considerados normais.

Nos experimentos realizados na propriedade em Itaguaí, o início dos sinais clínicos após a ingestão espontânea da planta foi de 42 horas (Caprino 5804, SAP 31955). 0 Caprino 5803 (SAP 31954) foi encontrado morto na baia no 3 o dia após ter sido levado ao pasto.

Nos experimentos realizados no SAP/PSA/UFRRJ, o início dos sinais clínicos após a administração da planta variou de $7 \mathrm{~h}$ a $46 \mathrm{~h} 45 \mathrm{~min}$.

A evolução da intoxicação em todos os experimentos (nos de ingestão espontânea e nos de administração controlada) variou de $3 \mathrm{~h} 6 \mathrm{~min}$ a $126 \mathrm{~h} 40 \mathrm{~min}$. Os animais apresentavam inicialmente um quadro clínico de inapetência, adipsia, apatia e relutância ao movimento. Posteriormente adotavam decúbito esternal e ao serem colocados em estação, mantinham os membros anteriores flexionados, apoiavam apenas os posteriores no chão até evolução para flexão dos quatro membros e seguia-se o decúbito lateral. A temperatura retal e as frequências cardíaca e respiratória permaneceram normais até próximo à morte. Os movimentos ruminais diminuíram e alguns animais apresentaram atonia próximo à morte. Um animal (Caprino 5805, SAP 31956) apresentou fezes diarreicas.

Quanto aos exames bioquímicos do soro sanguíneo dos animais intoxicados experimentalmente, a atividade de ALT e AST tendeu a normalidade sendo observadas variações discretas em alguns animais. Foi observado aumento progressivo das concentrações de ureia e creatinina na maioria dos animais. A atividade de CK esteve aumentada em todos os animais, em maior ou menor grau. A atividade de LDH mostrou comportamento variável em relação à CK. 
Quadro 4. Bioquímica sanguínea na intoxicação experimental por Metternichia princeps em caprinos

\begin{tabular}{|c|c|c|c|c|c|c|c|c|c|c|c|c|c|c|c|c|c|c|c|c|c|c|c|c|c|}
\hline \multirow{2}{*}{$\begin{array}{l}\text { Parâmetros } \\
\text { clínicos }\end{array}$} & \multirow{2}{*}{$\begin{array}{l}\begin{array}{l}\text { Caprino } 5801 \\
\text { (SAP 31799) }\end{array} \\
\frac{\mathrm{T} 1}{}\end{array}$} & \multicolumn{3}{|c|}{$\begin{array}{c}\text { Caprino } 5802 \\
\text { (SAP 31800) }\end{array}$} & \multicolumn{2}{|c|}{$\begin{array}{c}\text { Caprino } 5804 \\
\text { (SAP 31955) }\end{array}$} & \multicolumn{2}{|c|}{$\begin{array}{c}\text { Caprino } 5805 \\
\text { (SAP 31956) }\end{array}$} & \multicolumn{2}{|c|}{$\begin{array}{l}\text { Caprino } 5806 \\
\text { (SAP 32234) }\end{array}$} & \multicolumn{3}{|c|}{$\begin{array}{c}\text { Caprino } 5807 \\
\text { (SAP 32235) }\end{array}$} & \multicolumn{4}{|c|}{$\begin{array}{c}\text { Caprino } 5808 \\
\text { (SAP 32238) }\end{array}$} & \multicolumn{3}{|c|}{$\begin{array}{c}\text { Caprino } 5810 \\
\text { (SAP 32245) }\end{array}$} & \multicolumn{3}{|c|}{ Caprino 5811} & \multicolumn{2}{|c|}{$\begin{array}{c}\text { Caprino } 5812 \\
\text { Controle }\end{array}$} \\
\hline & & $\mathrm{T} 1$ & $\mathrm{~T} 2$ & T3 & T0 & $\mathrm{T} 1$ & T0 & $\mathrm{T} 1$ & T0 & $\mathrm{T} 1$ & T0 & $\mathrm{T} 1$ & T3 & T0 & T1 & $\mathrm{T} 2$ & T3 & T0 & $\mathrm{T} 1$ & T3 & T0 & $\mathrm{T} 1$ & T3 & T0 & $\mathrm{T} 1$ \\
\hline ALT & - & - & - & - & 00 & 03 & 06 & 06 & 40 & 40 & 06 & 27 & 84 & 13 & 06 & 06 & 10 & 00 & 03 & 13 & 03 & 16 & 10 & 13 & 06 \\
\hline AST & - & - & - & - & 66 & 123 & 76 & 89 & 193 & 230 & 103 & 196 & 316 & 220 & 133 & 123 & 99 & 66 & 53 & 593 & 53 & 86 & 110 & 130 & 96 \\
\hline UREIA & 155 & 108 & 181 & 274 & 21 & 52 & 11 & 22 & 50 & 49 & 62 & 83 & 159 & 41 & 212 & 238 & 248 & 46 & 182 & 176 & 61 & 101 & 63 & 69 & 26 \\
\hline CREATININA & 5,7 & 7,1 & 9,1 & 11,9 & 0,8 & 3,2 & 1,8 & 1,0 & 1,0 & 3,1 & 1,2 & 3,7 & 4,6 & 0,8 & 9,7 & 10,1 & 10,6 & 1,4 & 7,1 & 6,6 & 1.2 & 7.0 & 1.7 & 1.9 & 1.5 \\
\hline CK & - & - & - & - & 400 & 130 & 96 & 56 & 519 & 769 & 573 & 1.343 & 1.513 & 20 & 333 & 933 & 1.026 & 550 & 230 & 76 & 170 & 282 & 20 & 283 & 20 \\
\hline DHL & - & - & - & - & 105 & 696 & 170 & 153 & 663 & 1.060 & 526 & 704 & 1.546 & 275 & 663 & 809 & 995 & 178 & 80 & 82 & 83 & 73 & 170 & 08 & 250 \\
\hline $\mathrm{Ca}$ & - & - & - & - & 6,9 & 7,0 & 8,8 & 8,3 & 8,2 & 9,5 & 8,4 & 9,2 & 10,4 & 6,9 & 6,9 & 6,4 & 6,5 & 6,9 & 6,9 & 7,7 & 9.2 & 8.6 & 8.7 & 7.8 & 8.5 \\
\hline $\mathrm{P}$ & 7,2 & 4,8 & 4,4 & 3,7 & 6,7 & 3,3 & 4,9 & 4,1 & 4,5 & 8,0 & 9,4 & 8,6 & 5,3 & 4,8 & 1,9 & 3,9 & 5,8 & 6,1 & 4,7 & 8,8 & 7.0 & 8.0 & 8.9 & 9.0 & 5.3 \\
\hline $\mathrm{Na}$ & - & - & - & - & 140 & 146 & 158 & 158 & 138 & 140 & -- & 160 & -- & 160 & 132 & 140 & 156 & 170 & 180 & 160 & 158 & 160 & 140 & 164 & 158 \\
\hline $\mathrm{K}$ & - & - & - & - & 3,6 & 4,0 & 4,0 & 3,0 & 4,0 & 5,1 & -- & 5,2 & -- & 6,1 & 4,1 & 5,0 & 5,6 & 06 & 03 & 5,4 & 5,8 & 5,7 & 6,2 & 6,0 & 5,8 \\
\hline
\end{tabular}

T0 = coleta de sangue antes da administração da planta; T1, T2 e T3 = coletas de sangue durante a evolução da intoxicação.

Quadro 5. Exame físico químico da urina na intoxicação experimental por Metternichia princeps

\begin{tabular}{ccccc}
\hline Caprino & Datas e horas da coleta & Densidade & PH & Proteína \\
\hline Caprino 5806 & $15.02 .201112: 30 \mathrm{~h}$ & 1.010 & 8,0 & + \\
(SAP 32234) & $16.02 .201110: 56 \mathrm{~h}$ & 1.030 & 6,5 & +++ \\
& $16.02 .201112: 00 \mathrm{~h}$ & 1.030 & 6,0 & +++ \\
Caprino 5807 & $16.02 .201111: 20 \mathrm{~h}$ & 1.020 & 8,5 & +++ \\
(SAP 32235) & $16.02 .201123: 00 \mathrm{~h}$ & 1.030 & 6,5 & +++ \\
& $17.02 .201100: 25 \mathrm{~h}$ & 1.030 & 6,5 & +++ \\
& $18.02 .201109: 40 \mathrm{~h}$ & 1.030 & 6,5 & +++ \\
Caprino 5808 & $18.02 .201109: 50 \mathrm{~h}$ & 1.030 & 6,0 & +++ \\
(SAP 32238) & $15.03 .201119: 48 \mathrm{~h}$ & 1.030 & 8,0 & +++ \\
& $16.03 .201109: 50 \mathrm{~h}$ & 1.025 & 8,0 & ++ \\
Caprino 5809 & $10.03 .201117: 30 \mathrm{~h}$ & 1.020 & 8,0 & ++ \\
& $14.03 .201108: 32 \mathrm{~h}$ & 1.015 & 8,0 & + \\
Caprino 5810 & $07.04 .201118: 45 \mathrm{~h}$ & 1.005 & 8,5 & + \\
(SAP 32245) & $13.04 .201111: 10 \mathrm{~h}$ & 1.020 & 7,5 & +++ \\
& $14.04 .201100: 50 \mathrm{~h}$ & 1.030 & 8,0 & ++ \\
Caprino 5811 & $07.04 .201116: 00 \mathrm{~h}$ & 1.015 & 8,0 & +++ \\
& $09.04 .201107: 50 \mathrm{~h}$ & 1.025 & 8,0 & +++ \\
& $10.04 .201111: 10 \mathrm{~h}$ & 1.020 & 8,0 & ++ \\
& $13.04 .201111: 05 \mathrm{~h}$ & 1.025 & 7,0 & ++
\end{tabular}

+ Alteração leve, ++ moderada, +++ acentuada.

As concentrações de cálcio, fósforo, sódio e potássio tenderam a normalidade em todos os animais intoxicados experimentalmente, mesmo naqueles em que foi caracterizada insuficiência renal. Hipocalcemia discreta foi observada em alguns animais. (Quadro 4)

0 exame físico-químico da urina, demonstrou, próximo à morte, uma tendência à diminuição do $\mathrm{pH}$ (em média de 7,5 para 6,0) e aumento da densidade (1010 para 1020) em todos os animais. (Quadro 5)

À necropsia destacaram-se edema de tecido adiposo perirrenal, rins pálidos com estriação esbranquiçada desde o córtex até a região medular, e fígado com evidenciação do padrão lobular.

Nos casos experimentais da intoxicação por M. princeps nos caprinos, as alterações histológicas também ocorreram principalmente no rim e em menor grau no fígado. Nos rins verificou-se em 8 dos 9 casos necrose tubular tóxica, com o mesmo aspecto que nos casos naturais acima descritos (Fig.11). Adicionalmente foi observada em 6 dos 9 caprinos picnose das células epiteliais de túbulos uriníferos; nesses casos a cromatina nuclear era bem concentrada e o citoplasma estava vacuolizado e, às vezes, os contornos

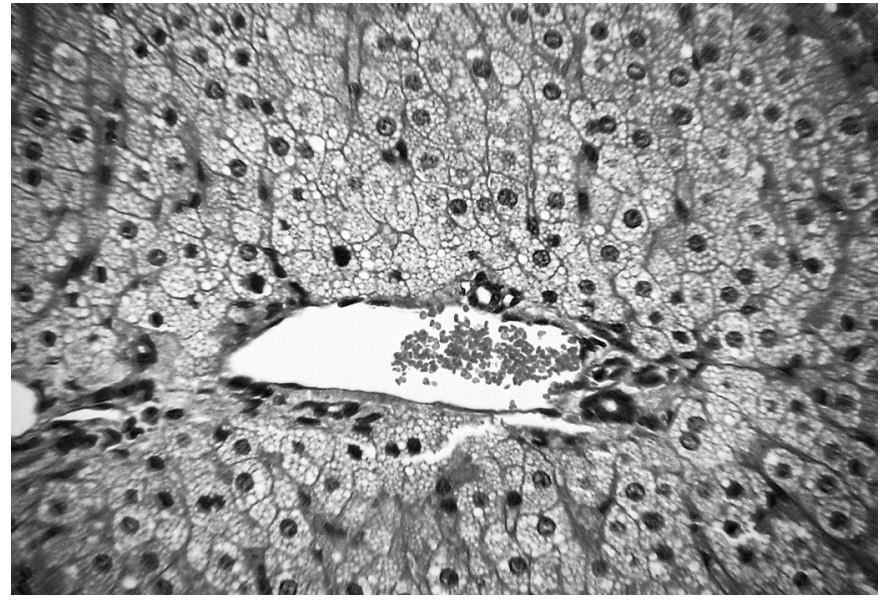

Fig.13. Acentuada vacuolização difusa de hepatócitos, na intoxicação experimental por Metternichia princeps. (Caprino 5801, SAP 31799). HE, obj.16x.

celulares pouco nítidos. Na luz dos túbulos uriníferos, tanto no córtex quanto na medula, havia presença de cilindros hialinos e precipitados de albumina, e somente em um caso havia neutrófilos e detritos celulares. Em quase todos os caprinos havia dilatação dos túbulos uriníferos com achatamento das células epiteliais, principalmente no córtex.

No fígado foi constatada vacuolização em vacúolos grandes, de intensidade leve a moderada e vacuolização em vacúolos pequenos, em outros casos. Em parte dos caprinos os hepatócitos tinham aspecto de células vegetais devido à tumefação (Fig.13). Os demais órgãos não apresentaram alterações significativas. A coloração pelo Tricrômico de Masson, utilizada em todos os rins, foi negativa para tecido conjuntivo. Detalhes da histopatologia constam no Quadro 6.

\section{DISCUSSÃO}

0 diagnóstico da intoxicação por Metternichia princeps baseou-se no histórico, no quadro clínico-patológico, nos exames laboratoriais, na observação de caprinos ingerindo a planta no pasto acusado de causar o problema, e na reprodução da doença pela administração controlada de $M$. princeps a caprinos.

No Brasil não havia descrição de intoxicação espontânea por plantas nefrotóxicas em caprinos. 


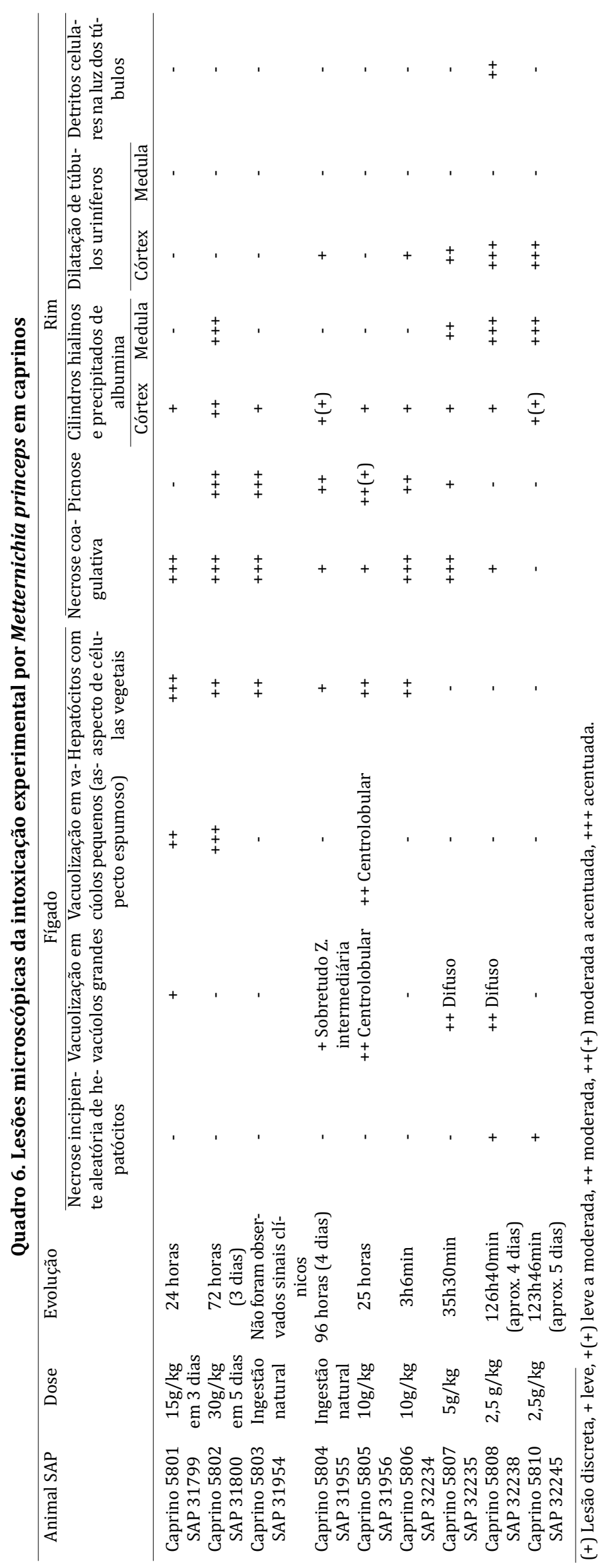

O quadro clínico-patológico da intoxicação natural observado nos caprinos foi semelhante à intoxicação experimental por M. princeps. 0 emagrecimento progressivo, a fraqueza muscular até a acentuada atrofia, a postura dos membros anteriores flexionados até a evolução de flexão dos quatro membros, foi encontrada em ambas as intoxicações.

Nos casos naturais os animais não apresentavam inapetência, ao contrário do observado nos casos experimentais.

A evolução do quadro de intoxicação natural nos caprinos variou de alguns dias até poucas semanas; nos animais intoxicados experimentalmente variou de poucas horas a aproximadamente uma semana. A razão para a evolução mais curta na intoxicação experimental talvez seja devido ao fato de os animais terem ingerido a planta em um curto espaço de tempo, enquanto que na intoxicação natural os animais ingeriam a planta no pasto num período mais longo, concomitantemente a outras fontes de alimentação.

Em relação aos exames bioquímicos do soro sanguíneo dos dois animais intoxicados naturalmente, o aumento da atividade da ALT a partir da segunda coleta pode estar correlacionado com a lesão muscular atrófica observada à necropsia. 0 aumento da concentração sérica de ureia nesses animais, analisado isoladamente, sugere condição pré-renal como causa (Kerr 2003), mas em associação com aumento da concentração de creatinina é compatível com insuficiência renal.

No que diz respeito aos exames bioquímicos do soro sanguíneo dos animais intoxicados experimentalmente, as discretas variações de ALT e AST são sugestivas de dano hepatocelular leve ou podem estar correlacionados com lesão muscular (Gonzáles \& Silva 2006), como ocorreram com os Caprinos 5806 e 5807. 0 aumento das concentrações de ureia e creatinina associados, vistos em 6 de 10 caprinos, são fortes evidências de insuficiência renal. Quando ocorre isoladamente, o aumento da concentração de ureia pode ser devido à condição pré-renal (Kerr 2003). 0 aumento na atividade de CK é consistente com lesão muscular (Thrall 2006), e a atividade da LDH ajuda a compreender a progressão ou regressão da lesão, porque aumenta em momento diferente da CK (Caprinos 5804). 0 aumento da atividade de LDH associado ao aumento da atividade de AST é compatível com manutenção/progressão da lesão (Caprinos 5806 e 5807). Não é esperada hiperfosfatemia na insuficiência renal em ruminantes, porque o rim não é o principal órgão de excreção de fósforo nesses animais (Gonzáles \& Silva 2006, Stockham \& Scott 2011a). A hipocalcemia pode ser relacionada, além da insuficiência renal, à hipoalbuminemia ou hipoproteinemia (Stockham \& Scott 2011b). As discretas variações observadas nas análises de sódio e potássio não aparentam estar correlacionadas diretamente com a função renal.

À necropsia, os casos naturais e experimentais também se assemelharam, sobretudo nas lesões relacionadas aos rins. Estavam presentes em ambos os casos a caquexia, o edema de tecido adiposo perirrenal, os rins pálidos com estriação esbranquiçada no córtex até a região medular.

As lesões microscópicas foram semelhantes entre os casos naturais e os da intoxicação experimental por $M$. 
princeps. A necrose de coagulação dos túbulos uriníferos esteve presente em grande parte dos animais de ambas as séries.

As intoxicações experimentais com $M$. princeps em coelhos e caprinos apresentaram diferenças significativas. No coelho havia predomínio de alterações cardíacas e hepáticas (Maran 2011). Nos caprinos, tanto nos casos naturais quanto experimentais de intoxicação, as alterações foram principalmente renais. Esta diferença pode ser explicada de duas maneiras, ou o coelho reage diferentemente ao princípio tóxico que o caprino, ou há mais de um princípio tóxico em $M$. princeps.

Numa comparação do quadro-clínico patológico entre M. princeps e as principais plantas nefrotóxicas brasileiras, a intoxicação por $M$. princeps guarda semelhanças com a intoxicação por Thiloa glaucocarpa em bovinos (Tokarnia et al. 1981), e por Amaranthus spp em bovinos (Tokarnia et al. 2012) e ovinos (Peixoto et al. 2003). Achados de necropsia como caquexia, edema do tecido adiposo perirrenal e lesões atribuídas à uremia, como ulcerações na língua, na faringe e no esôfago, e ao exame histológico, necrose tubular renal encontrada nos caprinos intoxicados por $M$. princeps, também são vistos nas intoxicações por T. glaucocarpa e Amaranthus spp. em bovinos. Os edemas subcutâneos e as alterações digestivas descritos na intoxicação por T. glaucocarpa e por Amaranthus spp. em bovinos não foram observadas nos caprinos intoxicados por M. princeps.

A intoxicação por Dimorphandra mollis também apresenta semelhanças à causada por $M$. princeps. Na intoxicação por ambas as plantas há, à necropsia, edema perirrenal, eventualmente edema subcutâneo, e necrose de coagulação dos túbulos uriníferos. (Tokarnia \& Dobereiner 1967).

No diagnóstico diferencial devem ser consideradas principalmente as intoxicações por Thiloa glaucocarpa, Amaranthus spp. e Dimorphandra mollis (Tokarnia et al. 2012) por suas semelhanças desde a evolução da doença até os achados microscópicos. Na intoxicação por Amaranthus spp., raramente há necrose de coagulação nos túbulos uriníferos (Ferreira et al. 1991), porém outras lesões encontradas nos rins como a presença de cilindros hialinos (Ferreira et al. 1991) são comuns tanto na intoxicação por Amaranthus spp. quanto na por M. princeps.

Ainda devem ser levados em consideração outros eventos que cursem com insuficiência renal aguda, como desidratação, desequilíbrios eletrolíticos, hipotensão sistêmica, hipoalbuminemia, vasculite, febre, septicemia, leptospirose e cirurgia ou anestesia prolongada. 0 uso de fármacos potencialmente nefrotóxicos (Belknap \& Pugh 2005) como aminoglicosídeos, tetraciclinas e sulfonamidas (Maxie \& Newman 2007) também devem ser considerados no diagnóstico diferencial.

\section{REFERÊNCIAS}

Barbará T. \& Carvalho L.A.F. 1996. Solanaceas nas Restingas do Estado do Rio de Janeiro: lista preliminar. Bolm Museu de Biologia Mello Leitão, Espírito Santo, 4:4-23.

Belknap E.B. \& Pugh D.G. 2005. Enfermidades do sistema urinário, p.217310. In: Pugh D.G. (Ed.) , Clínica de Ovinos e Caprinos. Roca, São Paulo. 528 p.

Caldas S.A., Prado J.S., Costa S.Z.R., Peixoto T.C., Brito M.F. \& Tokarnia C.H. 2011. Intoxicação natural por Metternichia princeps (Solanaceae) em caprinos. XV Enapave, Goiânia, GO. (Resumo)

Ferreira J.L.M., Riet-Correa F., Schild A.L. \& Méndez M.C. 1991. Intoxicação por Amaranthus spp. (Amaranthaceae) em bovinos no Rio Grande do Sul. Pesq. Vet. Bras. 11(3/4):49-54.

Gonzáles F.H.D. \& Silva S.C. 2006. Perfil bioquímico sanguíneo, p.313-358. In: Ibid. (Eds), Introdução à Bioquímica Clínica Veterinária. Editora da UFRGS, Porto Alegre.

Kerr M.G. 2003. Avaliação com base em órgãos individuais, p.239-249. In: Ibid. (Ed.), Exames Laboratoriais em Medicina Veterinária: bioquímica clínica e hematologia. Roca, São Paulo.

Lopes R.C., Coelho M.A.N. \& Andreata R.H.P. 2004. Plantas ornamentais ocorrentes na Mata Atlântica do Morro Alto Mourão, Niterói/Maricá, Rio de Janeiro. Publ. Avul. Museu Nacional 102:1-16.

Lorenzi H. 2009. Árvores Brasileiras: manual de identificação e cultivo de plantas arbóreas nativas do Brasil. Vol.3. Instituto Plantarum, Nova Odessa, SP. 368p.

Maran N.B. 2011. Intoxicação experimental por Metternichia princeps (Solanaceae) em coelhos. Dissertação de Mestrado, Instituto de Veterinária, Universidade Federal Rural do Rio de Janeiro, Seropédica, RJ. 49p.

Maxie M.G. \& Newman J.S. 2007. Urinary system, p.425-522. In: Maxie M.G. (Ed.), Jubb, Kennedy and Palmer's Pathology of Domestic Animals. Vol.2. $5^{\text {th }}$ ed. Saunders Elsevier, Edinburgh.

Peixoto P.V., Brust L.A.C., Brito M.F., França T.N., Cunha B.R.M. \& Andrade G. B. 2003. Intoxicação natural por Amaranthus spinosus (Amaranthaceae) em ovinos no Sudeste do Brasil. Pesq. Vet. Bras. 23(4):179-184.

Schwirkowski P. 2009. Lista de espécies vegetais de Mata Atlântica, floresta ombrófila mista (Mata Araucária) e Floresta ombrófita densa. Disponível em <http://sites.goole.com/site/florasbs/home> Acesso em 23 abr.

Stehmann J.R., Mentz L.A., Agra M.F., Vignoli-Silva M. \& Giacomin L. 2010. Solanaceae, p.1633-1638. In: Forzza R.C. et al., mais de 20 autores (Eds), Catálogo de Plantas e Fungos do Brasil. Instituto de Pesquisas Jardim Botânico, Rio de Janeiro.

Stockham S.L. \& Scott M.A. 2011a. Sistema urinário, p.342-411. In: Ibid. (Eds), Fundamentos de Patologia Clínica Veterinária. Guanabara Koogan, Rio de Janeiro.

Stockham S.L. \& Scott M.A. 2011b. Cálcio, fósforo, magnésio e seus hormônios reguladores, p.496-532. In: Ibid. (Eds), Fundamentos de Patologia Clínica Veterinária. Guanabara Koogan, Rio de Janeiro.

Thrall M.A. 2006. Diagóstico laboratorial da lesão muscular, p.391-393. In: Ibid. (Ed.), Hematologia e Bioquímica Clínica Veterinária. Roca, São Paulo.

Tokarnia C.H. \& Döbereiner, J. 1967. Intoxicação experimental pela fava de "faveira" (Dimorphandra mollis Benth.) em bovinos. Pesq. Vet. Bras. 2:367-373.

Tokarnia C.H., Brito M.F., Barbosa J.D., Peixoto P.V. \& Döbereiner J. 2012. Plantas nefrotóxicas, p.205-221. In: Ibid. (Eds), Plantas Tóxicas do Brasil. $2^{\text {a }}$ ed. Editora Helianthus, Rio de Janeiro.

Tokarnia C.H., Döbereiner J., Canella C.F.C, Couceiro J.E.M., Silva A.C.C. \& Araújo F.V. 1981. Intoxicação de bovinos por Thiloa glaucocarpa (Combretaceae) no Nordeste do Brasil. Pesq. Vet. Bras. 1(4):111-132. 